Tourism in Analysis

DOI: http://dx.doi.org/10.11606/issn.1984-4867.v27i3p696-713

\title{
Nuevos Conceptos, Nuevas Realidades: revisando el rol de la belleza en la formación del turismo oscuro
}

\author{
New concepts, new realities: a review on the role of beauty in dark tourism \\ formation
}

Novos conceitos, novas realidades: uma revisão do papel da beleza na formação do turismo escuro

Jean Henrique Costa ${ }^{1}$

Maximiliano E. Korstanje ${ }^{2}$

\begin{abstract}
Resumen
Este artículo tiene como objetivo discutir el concepto de belleza a través de la teoría estética de Theodor Adorno y la noción de sublime en Kant. El turismo clásico priorizaba una idea apolínea de belleza, que con el tiempo ha cedido a formas mórbidas en el que el sufrimiento se ha transformado en el principal atractivo. El producto sol y playa ha sido reemplazado por visitas al Museo del Holocausto en Auschwitz, o a lugares plagados de pesar y sufrimiento. En este sentido, se discute la significación de la estética inscripta en la filosofía marxista de Adorno la cual se sitúa como un campo fértil para comprender el rol que representa el espectáculo del desastre en los medios de comunicación. En segundo lugar, indagamos la manera en la cual el llamado "turismo oscuro" ha estado trabajado en la literatura académica, sea como una tendencia sádica de una sociedad que ha perdido la sensibilidad al dolor del otro, sea como una forma de controlar y disciplinar a la muerte. Si la Escuela de Frankfurt y Theodor Adorno se encontraban preocupados por la predominancia de los valores estéticos en un mundo cada vez más sensual, no menos cierto es que necesitamos repensar los objetos explotados por el turismo oscuro, los cuales se separan de la lógica cultural industrial para abrazar la lógica de la emancipación. Partiendo de la base que la memoria implica libertad, ¿hasta qué punto podemos juzgar el mensaje que transmiten estos sitios como verdaderos iconos de autenticidad? Una lectura de Adorno no solo nos permite responder estas preguntas, sino que nos permite dilucidar sobre el núcleo perverso del turismo oscuro.
\end{abstract}

Palabras-clave: Estética; Concepto de belleza; Turismo oscuro; Desastre.

\footnotetext{
${ }^{1}$ Doutor em Ciências Sociais pela Universidade Federal do Rio Grande do Norte (PGCS/UFRN). Mestre em Geografia pela Universidade Federal do Rio Grande do Norte (UFRN). Especialista em Demografia pela Universidade Federal do Rio Grande do Norte (UFRN). Docente da Universidade do Estado do Rio Grande do Norte (UERN). Professor permanente do Programa de Pós-Graduação em Ciências Sociais e Humanas (PPGCISH/UERN). Mossoró, Rio Grande do Norte, Brasil. E-mail: prof.jeanhenriquecosta@gmail.com

2 Profesor adjunto da Universidad de Palermo, Argentina. Pesquisador da CERS Universidad Buenos Aires. Buenos Aires, Buenos Aires, Argentina. E-mail: mkorst@palermo.edu
} 
Tourism in Analysis

\begin{abstract}
This article intends to discuss the concept of beauty based on Theodor Adorno's aesthetic theory and Kant's notion of the sublime. Classic tourism prioritized an Apollonian sense of beauty, which, with time, yielded to morbid forms where suffering has become the main attraction. The sea and sun product have been replaced by visits to the Holocaust Museum in Auschwitz or other places of pain and death. Therefore, the aesthetic significance inscribed in Adorno's Marxist philosophy, which poses as a fertile ground to understand the role of the spectacle of disaster in communications, is discussed. Secondly, we delve into how dark tourism is addressed in specialized studies, whether as a new sadist tendency of a society where sensibility for others' suffering has declined, or as a mechanism to control and rule death. If Frankfurt School and Adorno were concerned by the advance of aesthetics in an increasingly sensual world, no less true is that we need to revisit the roots of dark tourism, which oscillates from the sense of alienation in Industrial world to the logic of emancipation. Starting from the premise that the memory implies freedom, to what extent can we judge this message as an icon of authenticity? Our understanding of Adorno allows us not only to answer these formulated questions, but also clarify the perverse center of dark tourism.
\end{abstract}

Keywords: Aesthetics; Beauty; Dark Tourism; Disaster.

\title{
Resumo
}

Este artigo tem como objetivo discutir o conceito de beleza a partir da teoria estética de Theodor Adorno e da noção de sublime em Kant. O turismo clássico priorizava uma ideia apolínea de beleza, que com o tempo cedeu a formas mórbidas nas quais o sofrimento se transformou no principal atrativo. O produto sol e mar vêm sendo substituído por visitas ao Museu do Holocausto em Auschwitz, ou a lugares atormentados de dor e sofrimento. Neste sentido, é discutida a significação da estética inscrita na filosofia marxista de Adorno, a qual se situa como um campo fértil para compreender o papel que desempenha o espetáculo do desastre nos meios de comunicação. Em segundo lugar, indagamos a maneira pela qual o denominado "turismo escuro" vem sendo trabalhado na literatura acadêmica, seja como tendência sádica de uma sociedade que tem perdido a sensibilidade perante a dor do outro, seja como uma forma de controlar e disciplinar a morte. Se a Escola de Frankfurt e Theodor Adorno se encontravam preocupados com a predominância de valores estéticos em um mundo cada vez mais sensual, não menos verdade é que necessitamos repensar os objetos explorados pelo turismo escuro, os quais são separados da lógica da indústria cultural para abraçar a lógica da emancipação. Assumindo a premissa de que a memória implica liberdade, até que ponto podemos julgar a mensagem que estes lugares de turismo escuro transmitem como verdadeiros ícones da autenticidade? Uma leitura de Adorno não somente nos permite responder a essas perguntas, mas também nos permite elucidar o núcleo perverso do turismo escuro.

Palavras-chave: Estética; Conceito de beleza; Turismo escuro; Desastre. 


\section{Introducción}

Luego del 11 de septiembre, el terrorismo se ha situado como el tema obligado del Occidente, lo que generó cambios sustanciales en las instituciones ya sea la organización sindical y la ley laboral, o en la forma de conceptualizar el mal y la belleza. Películas de terror, como Hostel (2005) o Masacre en Texas (1974), evidenciaban una extraña obsesión por la tortura y el enemigo interno. Miles de turistas visitaban el Ground Zero de Nueva York, como si fuese la meca de la lucha antiterrorista. En efecto, si nuestros abuelos pasaban sus vacaciones en verdaderos paraísos junto a las bondades del agua y la playa, nuestros contemporáneos prefieren lúgubres destinos, si se quieren mórbidos, donde la muerte y el sufrimiento humano se posicionan como principales atracciones (LENNON; FOLEY, 2000; YUILL, 2004; STONE; SHARPLEY, 2008; WILSON, 2008). Ello sugiere que el concepto mismo de atracción y belleza, luego del 11 de septiembre, ha cambiado en forma sustancial.

Por lo expuesto, este artículo tiene como objetivo discutir el concepto de belleza en el mundo del llamado "turismo oscuro" (dark tourism) a través de la teoría estética de Theodor Adorno y la noción de sublime en Kant. En este sentido, se discute la noción de estética inscripta en la filosofía marxista de Adorno que se presenta como un campo fértil para la compresión de esta suerte de la estética del desastre en los medios de comunicación. Alegóricamente las industrias culturales (y del turismo) aluden al desastre para reciclar territorios y estructuras que de otra forma quedarían inmutables. Siguiendo la lógica de la destrucción creativa, el turismo permite crear valor e interés por sitios que de otra forma quedarían en el anonimato. En segundo lugar, este ensayo discute cómo el turismo oscuro ha estado trabajado en la literatura académica, sea como una tendencia sádica de una sociedad que ha perdido la sensibilidad al dolor del otro, sea como una forma de controlar y disciplinar a la muerte. En consideración final, si la Escuela de Frankfurt y Theodor Adorno se encontraban preocupados por la predominancia de los valores estéticos en un mundo cada vez más sensual, no menos cierto es que necesitamos repensar los objetos explotados por el turismo oscuro, los cuales se separan de la lógica cultural industrial para abrazar la lógica de la emancipación. Partiendo de la base que la memoria implica libertad, ¿hasta qué punto podemos juzgar el mensaje que transmiten estos sitios como verdaderos iconos de autenticidad? Una lectura de Adorno no solo nos permite responder estas preguntas, sino que dilucida sobre el núcleo perverso del turismo oscuro. 


\section{La Estética en Theodor Adorno}

En sus Notas de Literatura I (2003), más específicamente en el texto "Lírica y Sociedad", Theodor Adorno señala que el contenido de un poema no es una simple demostración de emociones, experiencias individuales y sentimientos subjetivos. Por lo contrario, estas experiencias solo se convierten en arte cuando, precisamente por la especificación que adquieren al recibir forma estética, ganan su participación en lo universal (ADORNO, 2003).

Según Zuin, Pucci y Ramos de Oliveira (2001), para Adorno, el arte no puede ser reducido al dominio del irracionalismo, del mero subjetivismo. Este tratamiento sería similar a las estrategias de la industria de la cultura, ya que se mantendría la conciencia cosificada. La concepción adorniana del arte - que busca escapar de la producción de la industria cultural - consiste en su universalidad, esencialmente social, capaz de presentar la "voz de la humanidad" a través de la construcción estética. Para Adorno, el arte, en lugar de ser la mera exposición de palabras y emociones, debe establecerlas, en cambio, como el conjunto de una sociedad, que tomada como una unidad en sí misma contradictoria, aparece en la obra. Busca demostrar que la obra de arte obedece la sociedad y que va más allá (ADORNO, 2003). El arte debe mostrar lo que la ideología deja en silencio. No puede ser puramente individual. En Adorno, el carácter social del arte debe mostrar, además de su individualidad estética, el anuncio de una situación diferente; debe permitir una reacción a la objetivación del hombre y del mundo. Según muestran Zuin, Pucci y Ramos de Oliveira (2001), en Adorno, no es un arte puro, sino algo como la escritura de la historia, la memoria de la posibilidad de la libertad y la promesa de una futura emancipación.

Freitas (2008), anclada en el pensamiento de Theodor Adorno, dice que el carácter fetichista del arte es necesario - expresado por el precepto "arte por el arte" (l'art pour l'art) -, teniendo en cuenta que garantiza su principio antisocial y asegura desprecio por las normas y los códigos preestablecidos. Por otro lado, paradójicamente, Adorno niega la idea del arte por el arte, diciendo que esteriliza su potencial crítico. Hay, entonces, un fuerte vínculo con la sociedad, no en el conjunto de su función social, sino debido al hecho de que la dinámica histórica de la relación entre los hombres se refleja en los problemas inherentes a las formas de arte contemporáneo (FREITAS, 2008). Por lo tanto, el arte se aleja y se aproxima de la sociedad para hablar su silencio. Como se expresa en su Teoría estética (2006), niega categórica 
y empíricamente determinaciones impresas y, sin embargo, se cierra en su propia sustancia una entidad empírica (ADORNO, 2006), es decir: el arte es por sí mismo y no lo es.

El arte solamente puede presumir de ser válido si se realiza una crítica implícita de las condiciones de producción; si recuerda la distancia privilegiada que mantiene estas condiciones, este valor no es válido al instante. Por lo contrario, el arte únicamente puede ser auténtico si reconoce, en silencio, hasta qué punto se ha comprometido a lo que se opone; pero tomar esta lógica demasiado debilita precisamente su autenticidad (EAGLETON, 1993). Por ende, como subraya Eagleton, el arte es al mismo tiempo un ser-para-sí y un ser-para-la-sociedad. De este principio básico, los productos de la industria cultural, en particular los más masivos, estandarizados y racionalizados, distinguen radicalmente. Perpetran exactamente lo contrario, es decir, acercarse a la sociedad para luego callar su voz.

Según Zuin, Pucci y Ramos de Oliveira (2001), la teoría estética de Adorno viene a demostrar que las obras de arte, además de despertar la belleza y el éxtasis, también deben causar asombro, dolor, esperanza y negación, así impresionan nuestra sensibilidad y presionan nuestra racionalidad. En la lectura de los autores, la filosofía no debe ser una “estetización”, mucho menos se necesita racionalizar el arte. La experiencia estética, entonces, es el "voltaje" entre los dos polos. Se radica, en la Dialéctica negativa (2009), un pasaje sinóptico de esta tensión: Arte y filosofía no tienen su elemento común en la forma o procedimiento configurador, pero en un modo de comportamiento que prohíbe la "pseudomorfosis". Los dos permanecen constantemente fieles a su propio contenido a través de su oposición; arte, en lo que se pone rígido contra sus significados; la filosofía, en la medida que no se adhiere a ninguna inmediatez (ADORNO, 2009).

Esta perspectiva renovada de Adorno se observa en Teoría estética, publicado póstumamente en 1971, trabajo en que, en un contexto marcado por los conflictos, el arte pudo internalizarlos y redactarlos como experiencia estética, y, para causar perturbaciones y trastornos de percepción, demostrar conocimiento de las condiciones de una realidad conflictiva (GINZBURG, 2003). La teoría filosófica general de Adorno, así como su concepción estética, se encuentra orientada a los traumáticos eventos de la Segunda Gran Guerra. Como infiere Eric Hobsbawm (1994), los fascismos han creado un gran shock en la historia pues han contribuido a la reformulación de una nueva historia, mucho más visual, estética y ajena a los hechos históricos como realmente sucedieron. Los fascistas no solo eran nacionalistas radicales, sino que 
fundaron una necesidad de trascendencia, asociada a la masculinidad, la guerra, el odio y la sangre. Como no podía ser de otra forma, Adorno y muchos intelectuales de izquierda se vieron ampliamente influidos por el avance y caída de este movimiento. A la estandarización industrial que Adorno experimentaba en su país anfitrión Estados Unidos se le sumaba la falta de una consciencia crítica que según él había llevado a Alemania a perpetrar uno de los mayores crímenes de la historia contra la población civil y vulnerada en sus principios más esenciales. En consecuencia, uno de los aspectos unciales en el pensamiento de Adorno es la raíz del mal y el rol de la propaganda. Bajo ciertas circunstancias, el arte podía ser reciclado como un refugio del poder propagandístico cuando se subordinaba a los intereses políticos. Su mecanización inevitablemente llevaría al fin de la crítica (posición que pone muy cerca a Adorno de Marcuse) y con ella a la estetización del desastre. Como bien infiere Wald (1987), muchos intelectuales arribados de Europa central quienes encuentran refugio en Estados Unidos comienzan a cambiar sus criticas originales, y una vez derrotado Hitler, consideran al estalinismo uno de los peores males contra la democracia republicana. Influenciados por la presencia de Trotsky en Méjico, Adorno y otros exponentes de su época ejercen una crítica interesante sobre la mecanización del poder y el rol que representa la estética en tal proceso. El aporte central de Adorno a la filosofía ha sido entre otros muchos puntos que en la modernidad lo estético confiere sobre el objeto un aura especial que permite su comercialización y que aliena a quien lo consume. La técnica que es útil como prolongación de las potencialidades humanas adormece al arte y sus principales características disruptivas.

\section{La estética del Desastre en los Medios de Comunicación}

Sin lugar a dudas, el pueblo alemán ha estado preocupado por la influencia ejercida por el periodismo y los medios masivos de comunicación en las sociedades industriales, y dentro de ellas muy especialmente en la forma de hacer política. No es para menos, luego de los efectos devastadores que han dejado en Europa en nazismo y las lecciones que han dado sobre manipulación de masas, una gran cantidad de cientistas sociales aunaron esfuerzos para determinar hasta qué punto la propaganda condiciona mentalmente a una persona (KATZ; FOULKES, 1962; TICHENOR; DONOHUE; OLIEN, 1970). En perspectiva, como bien lo ha demostrado Noelle Neumann en La espiral del silencio (1995), una gran cantidad de 
personas han desarrollado un profundo miedo al aislamiento, por lo cual, eso incluye no ser segregados por los propios pares. Por este motivo, cuando se detecta que un valor o regla es percibido por la mayoría como satisfactorio, las personas desarrollan una valoración positiva del objeto mencionado con el fin de acercarse emocionalmente a sus pares. Ante un tema que es tendencia, el sujeto puede mentir y esconder sus propios sentimientos en favor de lo que piensa el grupo, o abrazar nuevas convicciones para no quedar relegado. Dentro de este contexto, la teoría de la comunicación ha hecho notables avances sobre la relación del ciudadano con sus medios. La teoría de la "aguja hipodérmica" sostenía que el mensaje transmitido por el medio, en su posibilidad de repetición, era suficiente para influir el pensamiento de un individuo, de igual forma un medicamento fluye por las venas cuando es inyectado por una jeringa. Para este corpus teórico, nuestras predisposiciones mentales, de alguna u otra forma, se diseñarían en forma externa por una red de medios y discursos que serían funcionales a los intereses de los grupos "hegemónicos" (LIPPMANN, 1997; PETERS, 1989; WHIPPLE, 2005). La discusión de esta tendencia académica miraba al nazismo como un proyecto exitoso de como la política puede ser llevada a los extremos de vulnerar no solo la ética humana, sino el principio mismo de realidad. La Escuela de Frankfurt, siguiendo este argumento, estaba terriblemente consternada por la experiencia de sus propios miembros con este cruel régimen. Por un lado, muchos de ellos habían sido perseguidos por el nazismo. Uno de sus más brillantes Theodor Adorno esbozaba su crítica sobre la cultura de masas que a su forma de ver adormecía la conciencia ciudadana.

Uno de los aspectos cruciales que configuraban la hegemonía de la cultura de masas sobre la sociedad consistía en la introducción del principio de instrumentalización como el eje central civilizatorio. Si bien, el cálculo hace a la máquina, el proceso lleva inevitablemente hacia la despersonalización. No aceptamos lo que nos dicen porque puedan disciplinarnos desde lo ideológico, sino por el contrario, porque han minado nuestra confianza en el otro (ADORNO; RABINBACH, 1975). Si el nazismo sentó las bases doctrinarias de la biopolítica, como bien lo explica Foucault, fue a razón de producir una muerte sistemática en aquellos a los que denostaba. Esta lógica de expansión y constricción lejos de desaparecer ha pasado de la Alemania nazi y los Estados Unidos en forma de un narcisismo darwinista en lo cual cada persona quiere sentirse único, bello y ejemplar (KORSTANJE, 2015). Como bien lo explica Yves Michaud en su tratado sobre el lujo, vivimos en un mundo donde la 
experiencia marca una diferencia entre el mundo de los elegidos y los condenados. Unos dotados de las particularidades para vivir la vida en forma alocada, los otros simplemente inmovilizados a un presente sin esperanza. Por egoísta y por solipsista, el capitalismo tiende a producir experiencias cada vez más individualistas que aíslan a la persona en una cosificación total (MICHAUD, 2015). Por su parte, Igor Kopytoff (2004) enfatiza el hecho de que en las economías capitalistas globalizadas la producción de "materias primas" alcanza no solo un aspecto cultural, sino también cognitivo dentro del universo de los consumidores. En un sentido, el discurso apunta a un individualismo que lleva a las personas a tomar decisiones que pueden transformarlas ellas mismas en mercancías, o materias primas. Siguiendo este argumento, Lash y Urry (1993) argumentan convincentemente que la fase capitalista global se caracteriza por la imposición de signos sobre los productos, signos cuyos dominios bordean lo simbólico. Lo estético ha tomado un protagonismo tan grande en la fase de producción global por medio del vaciamiento del sentido. Los hechos se imponen sobre la interpretación de la realidad, en conjunción a una modernidad reflexiva, en la cual tiempo y espacio asisten a nuevas reconfiguraciones. Si el tiempo estaba legalmente sujeto al territorio, en la modernidad global la economía del deseo, asociada a revoluciones tecnológicas en materia de movilidad, ha coadyuvado en nuevos valores que sitúan lo estético por encima de lo cronológico. Tanto la trayectoria de los objetos como la necesidad de movilidad han precipitado a un vaciamiento del espacio limitando las relaciones sociales a mediadores simbólicos. Desde el momento en que la economía se acopla al poder del signo, la imagen irrumpe subordinando todos los valores sociales a la "representación". Las materias primas no solo son de bajo costo debido al gran componente simbólico que llevan consigo (café de Colombia, tango de Argentina, vino de Francia), sino que denota un riesgo que no ha sido contemplado por los economistas, la merma en los recursos económicos sustentables (LASH; URRY, 1993). En este punto, es por demás interesante el abordaje de Korstanje (2016) en The Rise of Thana Capitalism and Tourism (2016a). El autor argentino considera que vivimos en una época donde la estética del desastre se ha transformado en uno de los criterios (materias primas) de mayor demanda dentro de las sociedades capitalistas de consumo. La sociedad del riesgo, que ponderaba el exceso de seguridad y prevención, ya ha quedado obsoleta, en post de una nueva teatralización de la tragedia que se transmite por los medios de comunicación, películas, y otras industrias del entreteniendo día y noche. De hecho, Korstanje agrega que 
los mismos parámetros de la belleza apolínea tal y cual fuese respetada por otras generaciones ha cedido frente a nuevas alegorías discursivas en el que la muerte y el sufrimiento representan un rol importante (KORSTANJE, 2016a).

En los últimos años, Jean Baudrillard llamaba la atención sobre la propensión de los medios por la producción de estéticas asociadas al desastre. Esta dinámica tenía como función principal la producción de pseudo-realidades cuyas consecuencias estaban enmarcadas dentro de la ficcionalidad de los medios. El peligro es impuesto discursivamente antes de que suceda de la misma forma que los Precogs, en la película Minority Report (2002), anticipaban los crímenes antes que ellos sucedían (BAUDRILLARD, 1981, 1993, 1997). Las sociedades posmodernas, nos explica Baudrillard, se encuentran orientadas a un futuro inexistente, a una pseudo-realidad que aun cuando irreal genera dinámicas palpables en la vida cotidiana de las personas. Naomi Klein sugiere que el capitalismo se ha reciclado a formas que usan el desastre como una excusa para que la elite imponga políticas financieras que de otra forma serían ampliamente rechazadas por la ciudadanía. Por medio de las industrias culturales y del turismo, el desastre permite reciclar territorios y estructuras que de otra forma quedarían inmutables (KLEIN, 2007).

\section{El concepto de Belleza en el Turismo Oscuro}

Aun cuando la filosofía ha tratado en forma extensa el tema de la belleza, ha sido el alemán Immanuel Kant quien lo ha discutido desde el temor que despierta la inmensidad. En la estética kantiana, la belleza se encuentra ligada a la sublimidad. Lo emocional en ambos adquiere un tono agradable, pero de diferente forma. Mientras lo bello adquiere condiciones de controlabilidad, lo sublime ha de ser siempre grande. Por otro lado, existen grados de lo sublime acorde con la conmoción que causa el sentimiento en nosotros: (1) lo sublime terrorífico, (2) lo noble y, (3) lo magnífico. Los grandes desiertos o paisajes desolados son (a menudo) causa de leyendas terroríficas, nos apabullan, nos da terror pensar quedarnos solos y aislados en esos parajes. En parte, lo bello puede ser pequeño, mientras que lo sublime encierra cierta magnificencia. En uno de sus pasajes, Kant señala: 
lo sublime ha de ser siempre grande; lo bello puede ser también pequeño. Lo sublime ha de ser sencillo; lo bello puede estar engalanado. Una gran altura es tan sublime como una profundidad; pero a esta acompaña una sensación de estremecimiento y a aquella una de asombro; la primera sensación es sublime terrorífica, y la segunda noble. La vista de las pirámides egipcias impresiona, según Halmquist refiere, mucho más de lo que por cualquier descripción podemos representarnos; pero su arquitectura es sencilla y noble. (KANT, 2007, p. 11)

Un desierto es particularmente terrorífico pues nos demuestra nuestra propia limitación, nos sentimos desprotegidos, pero no por eso podemos dejar de admirarlo, de vernos atraídos por él. Por ende, la contribución de Kant al concepto de belleza radica en que tanto lo terrorífico como lo bello producen atracción, y es ese el punto que está de manifiesto en el turismo oscuro. Se ha dado un debate ético en torno al fenómeno ya que las aguas se encuentran divididas. Un grupo sugiere que el turismo oscuro es una tendencia sádica de una sociedad que ha perdido la sensibilidad al dolor del otro (BAUDRILLARD, 2006; BLOOM, 2000), mientras otro grupo sostiene que se trata de una forma de controlar y disciplinar a la muerte (LENNON; FOLEY, 2000; MILES, 2002; STONE; SHARPLEY, 2008). Estos espacios de consumo tienen a la muerte o al sufrimiento como su principal forma de expresión. En este sentido, parte de los visitantes se encuentran motivados por diferentes objetivos. Ello hace a la investigación aplicada particularmente difícil por dos motivos centrales. En primer lugar, existe una limitación inherente en pensar los fenómenos por lo que dicen o piensan las personas. En parte porque la gente no sabe las causas de sus sentimientos o simplemente miente; por el otro, la cantidad de segmentos que se corresponde al turismo oscuro genera muchas confusiones en los expertos a la hora de determinar cuáles son sus causas. Biran, Poria y Oren (2011) comprenden que la literatura especializada ha demostrado algunas inconsistencias a la hora de comprender la "thanaptosis", piedra angular por la cual la muerte se hace experiencia en el otro. Como aquellos segmentos de turistas que buscan consumir tradición e historia, el turismo oscuro ejerce una gran atracción por "la muerte", pero una mayor por la "autenticidad". Los sitios que emulan batallas o episodios que en realidad existieron en otros lugares son considerados de menor valía respecto a los verdaderos lugares en donde sucedió el evento. Cohen (2011) argumenta convincentemente que el turismo oscuro sirve como instrumento pedagógico para dar un mensaje a la sociedad, y que éste es más o 
menos creíble dependiendo de la autenticidad del espacio. Para Friedrich y Johnston (2013), el turismo oscuro es una forma de rememorar y controlar los efectos negativos de la muerte. Si los sobrevivientes se sienten olvidados deben ser recordados, pues son "como los souvenirs", testigos vivientes del desastre. Las comunidades expresan un gran sufrimiento cuando son azotadas por eventos como ataques terroristas, o desastres naturales. El turismo oscuro funcionaría como un hito que da una lección a la comunidad.

En un reciente trabajo, la profesora Rodanthi Tzanelli (2016) de la Universidad de Leed, en Reino Unido, sostiene que tanto el turismo oscuro como las visitas a zonas de pobreza extrema (slum tourism) tienen como objetivo central captar y entretenerse con el sufrimiento ajeno. La inflación de riesgos que agobia a los ciudadanos de las principales metrópolis toma un sentido de control que es impuesto por alegorías discursivas. La fascinación por los espacios de desastre se corresponde con el poder alegórico del cine el cual forma por medio del espacio turístico un sentido de exclusividad. Mediante la estética del turismo oscuro (dark tourism), se puede obtener una destrucción creativa que recicle los efectos indeseados del desastre en un producto consumible y orientado a una demanda internacional. A la vez que un desastre o evento catastrófico destruye una comunidad, se sienta las bases para la producción de una nueva alegoría que con el tiempo se transformará en un destino turístico. Lo mismo se aplica a la pobreza extrema (slum tourism) o visitas a favelas, ranchadas o villas miserias situadas en diversas partes de América del Sur, Sudáfrica, La India, etc. Los siglos XIX y XX fueron el centro de operaciones de diversas potencias europeas las cuales decidieron intervenir políticamente en forma directa en diversos países periféricos, y al hacerlo expandieron una lógica de la explotación que dio como resultado a la modernidad, la movilidad y el turismo. Por ende, existe una carga interna de crueldad en el acto de hacer turismo que, según Tzanelli, se traduce en la forma en la cual el cine retrata al Otro no europeo, y desliga a Europa de sus responsabilidades directas o indirectas en los genocidios cometidos (TZANELLI, 2016).

Mary Beth Griggs (2014) reflexiona sobre la necesidad del ciudadano moderno de alejarse de la seguridad que confiere el estado en su sociedad, hacia espacios de guerra, muerte y destrucción. Las fronteras sirias, o campamentos militares en contienda, son algunos de los ejemplos que dejan atónitos a los especialistas. Esta suerte de nuevo turismo obedece 
a indicadores profundos y cambios culturales precedentes que deben ser discutidos. En el discurso de los turistas que visitan esta clase de sitios prima la idea de "haber estado ahí". Por último, Korstanje (2016) sugiere que el turismo oscuro alimenta una suerte de narcisismo fagocitado por el capitalismo moderno en lo cual la muerte es un criterio de exclusividad para quien continúa vivo. En efecto, el capitalismo moderno se ha expandido exitosamente gracias a la imposición de un darwinismo social en el que todos luchan contra todos por los recursos en merma. Este juego no solo favorece a la elite financiera, sino que además marca a fuego el rol de las instituciones que pone en descubierto como el ciudadano debe ser cogestor de sus propios riesgos. En esta fase del capitalismo, la vida es vista como una gran competencia en la cual la muerte de los otros fortalece el ego, pues a pesar de todo es quien continúa en carrera. El turismo oscuro es parte de un fenómeno que acusa recibo de cambios estructurales en las instituciones modernas. Las personas sienten felicidad cuando se consideran exclusivas, y la muerte de los demás parece estar orientado a fomentar en forma adictiva esa sensación.

\section{Conclusión}

Tal como infería Veblen, en La clase ociosa (1974), las sociedades se estructuran acorde a clases bien definidas, las cuales se articulan según su proximidad a los medios productivos. En este sentido, se da una asociación directa entre producción y concepción cultural que amerita ser discutida. Para Veblen (1974) con el paso del tiempo, todas las clases que forman a la sociedad tenderán a estructurarse en dos polos opuestos: la clase productiva-técnica y la ociosa. Si la primera apunta al "trabajo productivo", la segunda se centra en "el mundo de los servicios". La "clase ociosa" emerge como fenómeno debido a la introducción del derecho de "expropiación", por medio de la cual se confiere al consumo "un aura de ejemplaridad. No solo por su apego a la hazaña, sino al consumo conspicuo, la clase ociosa emula valores, códigos, normas y modales para adoctrinar a las clases productivas. El arte en este sentido, lejos de conformarse como un instrumento de quiebre, es en Veblen una forma estética monopolizada por la "clase ociosa". En forma complementaria, Pierre Bourdieu (2000) considera que toda práctica se encuentra inserta en el "habitus", el cual regula la norma mediante agencia. Cuando se toma una decisión no solo el rol es esencial, sino la configuración de una 
matriz cultural, que antecede a ese rol, permite al sujeto darle sentido a su decisión. La regla de todo juego se internaliza en el habitus, el cual no es otra cosa que un manual de instrucciones para que el sujeto se comporte acorde a lo que la sociedad espera de él. Para que exista, internamente, un correcto funcionamiento entre las clases, el habitus introduce "un elemento importante", que permite ordenar sistémicamente el papel de cada clase en el aparato productivo: la distinción. A diferencia de Veblen, Bourdieu entiende que la disciplina, lejos de ser un instrumento de control, apela a un mecanismo de clasificación el cual confiere al especialista un ámbito jurídico y normativo específico para una acción determinada. En otras palabras, la diferencia dada por la titulación abre el camino para la producción de nuevas diferencias que refuerzan el discurso de la distinción. Si las clases confrontan unas con las otras, eso se debe a dos elementos esenciales, el gusto y el prestigio. Visitar el Museo del Holocausto, beber un buen vino, apreciar una obra de arte se corresponden con intentos de apropiación simbólica que legitima la superioridad de una clase respecto a otras (BOURDIEU, 2000).

Este nuevo segmento que se denomina turismo oscuro, ofrece una nueva forma (aun cuando no por eso menos patológica) de ver la belleza. La muerte se ha transformado, en lugar de un criterio negado como sugería el psicoanálisis lacaniano, en una verdadera atracción. No obstante, lejos de reflexionar sobre el sufrimiento ajeno, los visitantes de esta clase de sitios refuerzan un sentimiento de superioridad sobre quienes han muerto. Desde el momento en que la vida es vista como una gran carrera, donde solo unos pocos tienen posibilidades reales de éxito, la muerte del otro nos da seguridad y felicidad. Con certeza, si las visitas a Auschwitz han tenido un aumento significativo en la demanda, ello se debe a la necesidad de reforzar la autoestima por medio del sufrimiento de otros. Patológicamente narcisista, el turismo oscuro también ha adquirido profundas e innumerables significaciones. El interés cultural en un lugar que significa el testimonio más reciente de nuestra barbarie histórica puede significar, por una parte, la posibilidad de crítica de la historia, la historia como escritura de la cultura, como pasado y el aprendizaje permanente. Auschwitz puede, de acuerdo con el diseño de la teoría estética de Adorno, impresionar a nuestra sensibilidad y pulse nuestra racionalidad siempre y cuando no quede cosificado al interés individual y narcisista. Es importante no olvidarse que Auschwitz es un primer paso para no permitir su regreso. El problema parte en que, por otro lado, el avance irreversible de la industria cultural, o mismo la expansión de la sociedad del espectáculo, instiga a pensar que la misma historia puede ser traicionada, 
materializada por las manos de la "fetichización" de la historia a través de la industria cultural. La obra de Adorno deja claro que lo que determina el funcionamiento de la industria cultural, en principio, no tiene conexión directa con el término "calidad", sino con la acumulación de capital y la maximización de la ganancia. Desde una perspectiva cualitativa, el avance capitalista ha sido exitoso por su capacidad de reciclar situaciones naturales en construcciones artificiales. Incluso la muerte se convierte en objeto de venta, como problematiza Zuin (2008), lo que refleja en el proyecto de la película holandesa Necrocam (2001). En esta película, un cadáver tendría una micro cámara en la tumba, y en línea el usuario de Internet podría controlar mediante termostato, proceso de descomposición del cuerpo (ZUIN, 2008). Por lo tanto, en la sociedad actual, incluso la muerte se transforma en espectáculo.

Lo que este ensayo ha intentado fue comprender precisamente esta doble posibilidad de interpretación del turismo oscuro (dark tourism), el cual expresa la necesidad de distinción de quienes pueden pagar por experimentar el sufrimiento de otros, pero que al hacerlo se distancian de éste permitiendo que el desastre pueda - dadas ciertas condiciones - sucederse nuevamente. En resumidas cuentas, la estetización de un campo de concentración nazi, abierto al turismo, al mercado, tiene amplias posibilidades de convertirse en un señuelo comercial de la historia, un simulacro para la reproducción del capital. Por otra parte, y la teoría estética de Adorno corrobora esto, el carácter social de esta estetización del terror a través del turismo puede mostrar en una construcción estética dado el anuncio de una situación diferente, permitiendo una reacción a la objetivación del hombre y del mundo. Los objetos explotados por el turismo oscuro pueden significar la escritura de la historia, la memoria de la posibilidad de la libertad y la promesa de una futura emancipación. Pueden impresionar nuestra sensibilidad y presionar nuestra racionalidad.

La muerte nos atrae porque nos genera un terror sublime (Kant) de la misma forma que el desierto. Ahora cuando esa atracción es mecanizada o commoditizada como supone Adorno esa sublimidad se transforma en espectáculo que no explica las causas del desastre, al entretener, pero no da ninguna lección para que el desastre no se repita en un futuro cercano. Por tal razón, es importante indagar acerca de cómo se construyen estas alegorías de la muerte o que lógicas persiguen, a la vez que su internalización permite o no la comprensión del lado oscuro de la historia. El concepto pedagógico alrededor de Auschwitz consiste en no permitir su repetición (ADORNO, 1998), pero visto el problema de ángulo anverso, si el turismo 
hace de la muerte trágica su principal valor, ¿cómo prevenirlo? En efecto, desde el momento en que el mercado se corresponde con el encuentro entre oferentes y demandantes, aquellos que confieran mayor valor a sus materias primas tendrán mayores posibilidades de éxito. El turismo oscuro y su crecimiento a claras nos hablan de la necesidad de consumir espacios de tragedia, pero al hacerlo no hay ninguna voluntad política de evitarlos. El desastre y sus nefastas consecuencias se han transformado en el valor central de lo que Korstanje (2016) ha llamado "capitalismo mortuorio", o Thana-Capitalism.

Por último, pero no por eso menos importante, George H. Mead (1934) hace unas décadas dijo que las ciencias sociales deben prestar atención al fenómeno que se da entre una audiencia y los medios de comunicación. Los ciudadanos se encuentran día a día más interesados en consumir noticias asociadas a crímenes y no pueden dejar de quejarse de la situación. La paradoja radica en que más allá de lo que el Estado haga, seguirán consumiendo este tipo de noticias. La explicación a esta problemática consiste en que el Self se encuentra ligado a otros, y toda amenaza que afecta a otro, que no soy yo, confiere preocupación, pero a la vez alivio. Korstanje (2016) sostiene que esta tendencia observada ya por Mead (1934), lejos de ser natural, es un signo de cómo funciona el capitalismo moderno y la afinidad que mantiene sus audiencias por el desastre. La visita a monumentos de desastres o catástrofes puede llevar consigo una impronta si se quiere educativa, empero en el fondo, el visitante intenta reforzar su sentimiento de superioridad respecto a un "otro "que ha muerto. En las sociedades seculares donde el más allá es una imposibilidad, morir es el peor de los fracasos. El clima de competencia total promovido por el capitalismo darwinista explica las desigualdades económicas vigentes donde pocos tiene mucho y el resto muy poco, por medio del progreso. Ser exitoso implica no solo adaptarse al riesgo y al cambio, sino además progresar. En este sentido, el pobre es visto como un "ser indigno" que en razón de tal ha perecido en la lucha por la supervivencia del más fuerte. Ideológicamente, comprendemos la vida como un gran juego o como una gran carrera en la cual la "caída del otro" nos alegra por la sencilla razón de que nos recuerda cuan especial somos, y que a pesar de los peligros seguimos en carrera hacia el premio mayor, la vida eterna. 
Tourism in Analysis

\section{Bibliografía}

ADORNO, T. W. Dialética negativa. Trad. Marco Antonio Casanova. Rio de Janeiro: Jorge Zahar, 2009.

. Educación para la emancipación. Madrid: Morata, 1998.

. Notas de literatura I. Trad. Jorge de Almeida. São Paulo: Duas Cidades; Editora 34, 2003.

. Teoria estética. Trad. Artur Morão. Lisboa: Edições 70, 2006.

ADORNO, T. W.; RABINBACH, A. G. Culture industry reconsidered. New German Critique, vol. 6, p. 12-19, 1975.

BAUDRILLARD, J. Cultura y simulacro. Buenos Aires: Kairós, 1993.

. El crimen perfecto. Madrid: Anagrama, 1997.

. El sistema de los objetos. Buenos Aires: Siglo XXI, 1981.

. Virtuality and events: the hell of power. Baudrillard Studies, vol. 3, n. 2, jul. 2006.

BIRAN, A.; PORIA, Y.; OREN G. Sought experience at dark heritage sites. Annals of Tourism Research, vol. 38, n. 3, p. 820-841, 2011.

BLOOM, T. Morbid-Tourism: a postmodern market niche with an example from Althrop. Norwegian Journal of Geography, vol. 54, n. 1, p. 29-36, 2000.

BOURDIEU, P. La distinción: criterio y bases sociales del gusto. Madrid: Taurus, 2000.

COHEN, E. H. Educational dark tourism at an in populo site: The Holocaust museum in Jerusalem". Annals of Tourism Research, vol. 38, n. 1, p. 193-209, 2011.

EAGLETON, T. A ideologia da estética. Trad. Mauro Sá Rego Costa. Rio de Janeiro: Zahar, 1993.

FRIEDRICH, M.; JOHNSTON, T. Beauty versus tragedy: thanatourism and the memorialisation of the 1994 Rwandan Genocide. Journal of Tourism and Cultural Change, vol. 11, n. 4, p. 302-320, 2013.

FREITAS, V. Adorno e a arte contemporânea. 2. ed. Rio de Janeiro: Jorge Zahar, 2008.

GINZBURG, J. Theodor Adorno e a poesia em tempos sombrios. ALEA, vol. 5, n. 1, p. 61-69, jan./ jun. 2003. 
Tourism in Analysis

GRIGS, M. B. People are traveling to War Zones for tourism. 2014. Disponible en: <http://www. smithsonianmag.com/smart-news/people-are-traveling-war-zones-tourism-180952051/?no-ist>. Visitado el: 14 jun. 2016.

HOBSBAWM, E. The age of extremes: a history of the World 1914-1991. New York: Vintage, 1994.

KANT, I. Lo bello y lo sublime. Madrid: Minimal, 2007.

KATZ, E.; FOULKES, D. On the use of the mass media as "escape": clarification of a concept. Public opinion quarterly, vol. 26, n. 3, p. 377-388, 1962.

KLEIN, N. La doctrina del shock: el auge del capitalismo del desastre. Barcelona: Paidós, 2007.

KOPYTOFF, I. The cultural biography of things. In: BUCHLI, V. (Ed.). Material culture: critical concepts in the social sciences. London: Routledge, 2004, p. 211.

KORSTANJE, M. E. A difficult world, examining the roots of capitalism. New York: Nova Science, 2015.

El diseño del capitalismo mortuorio, de la cultura del desastre al narcisismo. Reflexiones Marginales, n. 32, p. 1-17, $2016 \mathrm{~b}$.

. Puntos esenciales del turismo oscuro, un debate conceptual. Gran Tour, n. 10, p. 23-35, jul./ dic. 2015.

. The rise of thana capitalism and tourism. Abingdon: Routledge, 2016a.

LASH, S.; URRY, J. Economies of signs and space. London: Sage, 1993.

LENNON, J.; FOLEY, M. Dark tourism: the attraction of death and disasters. London: Thomson Learning, 2000.

LIPPMANN, R. P. Speech recognition by machines and humans. Speech communication, vol. 22, $\mathrm{n}$. 1, p. 1-15, 1997.

MEAD, G. H. Mind, self and society. Chicago: University of Chicago Press, 1934.

MICHAUD, Y. El nuevo lujo: experiencias, arrogancia, autenticidad. Buenos Aires: Taurus, 2015.

MILES, W. Auschwitz: museum interpretation and Darker Tourism. Annals of Tourism Research, vol. 29, n. 4, p. 1175-1178, 2002.

NEUMANN, N. La espiral del silencio. Buenos Aires: Paidos, 1995. 
Tourism in Analysis

PETERS, J. D. Democracy and mass communication theory: Dewey, Lippmann, Lazarsfeld. Communication, vol. 11, n. 3, p. 199-220, 1989.

STONE, P.; SHARPLEY, R. Consuming dark-tourism a thanatological perspective. Annals of Tourism Research, vol. 35, n. 2, p. 574-595, 2008.

TICHENOR, P. J.; DONOHUE, G. A.; OLIEN, C. N. Mass media flow and differential growth in knowledge. Public opinion quarterly, vol. 34, n. 2, p. 159-170, 1970.

TZANELLI, R. Thana tourism and cinematic representation of risk. Abingdon: Routledge, 2016.

VEBLEN, T. La clase ociosa. Ciudad de México: Fondo de Cultura Económica, 1974.

WALD, A. M. The New York intellectuals: the rise and decline of the anti-Stalinist left from the 1930s to the 1980s. North Carolina, NC: UNC Press Books, 1987.

WHIPPLE, M. The Dewey-Lippmann debate today: communication distortions, reflective agency, and participatory democracy. Sociological Theory, vol. 23, n. 2, p. 156-178, 2005.

WILSON, J. Z. Prison: cultural memory and dark tourism. New York: Peter Lang, 2008.

YUILL, S. M. Dark tourism: understanding visitor motivation at sites of death and disaster. 2004. Tesis (Doctoral) - Texas A\&M University, Texas, 2004.

ZUIN, A. Á. S. Morte em vídeo: Necrocam e a indústria cultural hoje. In: DURÃO, F. A.; ZUIN, A.; VAZ, A. F. (Orgs.). A indústria cultural hoje. São Paulo: Boitempo, 2008.

ZUIN, A. Á. S.; PUCCI, B.; RAMOS DE OLIVEIRA, N. Adorno: o poder educativo do pensador crítico. 3. ed. Petrópolis: Vozes, 2001.

Recebido em: 30/04/2016 (1 ${ }^{\mathrm{a}}$ versão) 31/07/2016 ( $2^{\mathrm{a}}$ versão)

Aprovado em: 15/08/2016 